\title{
Informal Breast Milk Sharing in a Muslim Country: The Frequency, Practice, Risk Perception, and Risk Reduction Strategies Used by Mothers
}

\author{
Güliz Onat and Hediye Karakoç
}

\begin{abstract}
Introduction: Turkey is the first and only Islamic country which has initiated a process to establish a milk bank. However, the effort was abandoned because of religious concerns. Informal breast milk sharing has become a practical alternative to some.

Research Aims: To document the religious concerned views and attitudes toward breast milk sharing and to determine risk reduction strategies of mothers in an Islamic country.

Materials and Methods: Participants comprised volunteers from relevant forums or members of social media groups on the Internet. The participants $(n=435)$ were divided into three groups: those who did not share milk $(n=371)$, donors $(n=48)$, and receivers $(n=16)$. A prepared questionnaire was used for each group as a data collection tool. Results: $14.7 \%$ of the participants were experienced in informal milk sharing. Seventy-five percent of the recipients and $85.4 \%$ of the donors did not enter into a written agreement. Religious rules on milk sharing were reflected in three ways: asking about the infant's gender, limiting the number of sharing parties to 3 , and knowing the identity of the donor or recipient. Of the participants, $77.3 \%$ believed that it was necessary to establish a milk bank in Turkey. However, $19.5 \%$ of the respondents reported that they would not feed their infant with donor milk because of reasons related to the issue of "milk kinship" in Islam.

Conclusions: Informal milk sharing is a reality and risks similar to those stated in the literature are undertaken. Milk sharing is frequently performed independent of religious concerns and commercial purposes, Comprehensive measures to minimize disease transmission are not routinely implemented.
\end{abstract}

Keywords: breast milk banks, milk donation, Islam, Turkey

$\mathbf{T}$ He World Health Organization states that the best option for infants who are not able to receive or who are not receiving sufficient breast milk from their own mothers is to supplement or provide milk obtained from a healthy wetnurse or a milk bank. ${ }^{1}$ The religious objection to this alternative relates to the Islamic tenet that consuming human milk builds a kinship bond between the infant and the donor's family and prohibits future marriage between such milkbrothers and sisters. $^{2}$

The Quran verse (Nisa 4:23) defines marriage restrictions as follows: "Prohibited to you [for marriage] are your mothers, your daughters, your sisters, your father's sisters, your mother's sisters, your brother's daughters, your sister's daughters, your [milk] mothers who have suckled you, their daughters (your foster-sisters)." This restriction is probably applied because of the potential transition of genetic material through breast milk. Thus, the marriages of milk siblings in the future may exert consequences similar to consanguineous marriages. ${ }^{3}$
The prime obstacle to the establishment of breast milk banks in Muslim countries results from a religious sensitivity in this potential consequence. Nevertheless, it is known that milk is shared through informal means. This study aims to understand the real-world milk sharing practices and concerns between families in a Muslim country.

\section{Type of Research}

The study was a descriptive and cross-sectional web-based research model.

\section{Definition of Terms}

We defined informal milk sharing as a personal noninstitutional arrangement made between a donor and recipient mother with or without a commercial basis. 


\section{Population and Sample of the Study}

The sample of the study consisted of 435 breastfeeding mothers who were members of various forums or social media groups on the Internet and who voluntarily accepted the invitation to participate in the study. The study period was between January 2017 and July 2018.

These questionnaires were prepared by the researchers and Charlotte Codron (she also helped with planning the methodology) in accordance with the scholarly literature. The questionnaire of Palmquist and Doehler ${ }^{4}$ was utilized as a basis. All study participants were asked 27 questions to determine the sociodemographic and obstetric history of the participants and to ascertain their thoughts about milk donation.

After the completion of the common section, the participants were directed to additional questions appropriately phrased according to their status as donors, recipients, and those who were not involved in milk sharing.

The question for the milk recipient families consisted of a total of 43 questions. A participant's thoughts and feelings in relationship to milk sharing were evaluated through 17 questions, the milk sharing risk perceptions were assessed through 7 questions, risk reduction strategies were estimated through 6 questions, and sociodemographic and obstetric characteristics were analyzed through 13 questions.

The questionnaire for the donor mothers encompassed 4 sections with a total of 32 questions. Opinions on breastfeeding and feelings on milk donation were collected through 13 questions, milk sharing risk perceptions were evaluated through 6 questions, risk reduction strategies were examined through 7 questions, and sociodemographic and obstetric characteristics were assessed via 13 questions.

The questionnaire for the study participants who were not involved in milk sharing consisted of 4 sections with a total of 19 questions. A respondent's reasons for not sharing milk were evaluated via 6 questions, and sociodemographic and obstetric characteristics were assessed through 13 questions.

\section{Statistical analysis}

The data were evaluated via descriptive statistics in SPSS 20.0 packaged software.

\section{Ethical Considerations of the Study}

Before starting the study, written permission dated November 25, 2016 and numbered E.3224 was obtained from the Ethics Committee.

\section{General Characteristics of the Participants}

A total of 435 breastfeeding mothers participated in the study. They were divided into three groups according to their last breastfeeding experience. "Recipient mothers" (16 persons) were defined as donor milk users, and they accounted for 3.7\% of the participants. Those who donated milk were labeled "donor mothers" (48 persons), and they constituted $11 \%$ of the participants. Mothers (371 persons) were not involved in milk sharing accounted for $85.3 \%$ of the participants.

The mean age of the participants was computed to be $31.09 \pm 4.6$ (recipients: $33.31 \pm 6.0$, donors: $31.10 \pm 4.8$, those not involved in milk sharing: $30.99 \pm 4.4$ ) years, and there was no statistically significant difference with regard to the mean age $(F=2.00 ; p=0.13)$. Of the participants, $86.9 \%$ were university graduates, $46.4 \%$ reported incomes equal to their expenses, and $36.3 \%$ claimed excess income. Of them, $62.5 \%$ previously experienced one pregnancy, $79.1 \%$ previously experienced one birth, and $78.9 \%$ had one living child. Of the participants, $44.8 \%$ underwent cesarean section with epidural/spinal anesthesia, and $26 \%$ experienced vaginal birth (Table 1).

\section{Results Related to Recipients}

Fifty percent of the recipient mothers fed their infants with both breast milk and formula, and $56.3 \%$ of them did not yet provide any supplementary food. Of the recipient mothers, $81.3 \%$ were first directed to the formula by health care workers.

Of the recipients, $62.5 \%$ found donor milk through sharing sites on the Internet, and $56.3 \%$ of them received the milk from someone on the Internet whom they did not know. The mean number of people from whom donor milk was received was $3.62 \pm 3.76$.

Milk insufficiency was reported as the primary cause of feeding an infant with donor milk, and $87.5 \%$ of the recipients participated in milk sharing because of this reason. The other most common reasons related to milk sharing were to prevent the use of formula at the rate of $62.5 \%$ and the fact that donor milk is the most natural way to feed an infant when mother's own milk is absent at the rate of $62.5 \%$. Seventyfive percent of the recipients stated that they usually froze and stored donor milk before giving it to the infant.

\section{Results Related to Donors}

Of the donor mothers, $93.8 \%$ fed their infants only with breast milk and shared their milk with $\sim 1.69 \pm 1.59$ people.

TABle 1. Sociodemographic and OBStetric Characteristics of the Participants

\begin{tabular}{|c|c|c|}
\hline Features & S & $\%$ \\
\hline \multicolumn{3}{|l|}{ Education status } \\
\hline University graduate & 378 & 86.9 \\
\hline High school graduate & 51 & 11.7 \\
\hline Middle school graduate & 6 & 1.4 \\
\hline \multicolumn{3}{|l|}{ Perception of income status } \\
\hline Equal income and expense & 202 & 46.4 \\
\hline More income & 158 & 36.3 \\
\hline More expense & 75 & 17.2 \\
\hline \multicolumn{3}{|l|}{ Total pregnancy } \\
\hline 1 & 272 & 62.5 \\
\hline 2 & 110 & 25.3 \\
\hline 3 and above & 53 & 12.2 \\
\hline \multicolumn{3}{|l|}{ Number of births } \\
\hline 1 & 344 & 79.1 \\
\hline 2 & 80 & 18.4 \\
\hline 3 and above & 11 & 2.5 \\
\hline \multicolumn{3}{|l|}{ Number of children living } \\
\hline 1 & 343 & 78.9 \\
\hline 2 & 82 & 18.9 \\
\hline 3 and above & 10 & 2.3 \\
\hline \multicolumn{3}{|l|}{ Type of birth } \\
\hline $\begin{array}{l}\text { Cesarean section with epidural/spinal } \\
\text { anesthesia }\end{array}$ & 195 & 44.8 \\
\hline Vaginal (normal delivery) & 113 & 26.0 \\
\hline Cesarean section with general anesthesia & 76 & 17.5 \\
\hline Vaginal birth with artificial pain & 51 & 11.7 \\
\hline
\end{tabular}


Their reasons for donating milk included the following: $83.3 \%$ desired to help someone and reported the production of excess milk, and $68.8 \%$ claimed that they did not need the milk that they expressed.

Of the donors, $56.3 \%$ donated their excess milk, $68.8 \%$ of them did not pass the predonation health screening, and $60.4 \%$ donated through the Internet sharing sites. Of the donors, $85.4 \%$ stated that health care workers did not recommend milk donation.

Of the donors, $83.3 \%$ asserted that they delivered milk to the recipient face-to-face, $95.8 \%$ used cool-packs or cooling containers while delivering milk, and $100 \%$ of the donors did not receive any money for the milk they donated.

\section{Results Related to Those Not Involved in Milk Sharing}

Of the mothers who were not involved in milk sharing, $81.4 \%$ fed their infants only with breast milk, and $56.3 \%$ gave their infants supplementary food.

The majority of breastfeeding mothers $(70.6 \%)$ who were not involved in sharing their breast milk did not consider donation or reception viable because of the possibility of a marriage of milk siblings, $33.4 \%$ felt that they produced just enough for their own infant, and $30.2 \%$ had never conceived of such an idea.

\section{Results Related to Islam and Milk Sharing}

Of the participants, $77.3 \%$ believed that it was necessary to establish a milk bank in Turkey, and $53.8 \%$ stated that, if there were a milk bank, they would feed their infant with the milk received from the bank. On the contrary, a total of $19.5 \%$ reported that they would not feed their infant with donor milk because of the concerns related to milk kinship in Islam. Of those not involved in milk sharing, $18.9 \%$ thought that establishing a milk bank in a Muslim country was inconvenient in terms of religion. This rate was $17.2 \%$ among all participants.

The other thoughts of the participants on milk sharing are shown in Table 2.

\section{Results Related to Opinions on Milk Sharing}

Of the participants who were not involved in milk sharing, $70.6 \%$ reported that they would like to donate milk, but only $42.9 \%$ stated that they were aware of milk sharing groups on the Internet. It was found out that $44.7 \%$ of the individuals would feed their infant only with the milk of someone they knew and $22.4 \%$ would not feed their infant with donor milk because of reasons related to milk kinship in Islam. $15.1 \%$ preferred to feed their infant with formula instead of someone else's milk, and $91.6 \%$ knew that disease-causing bacteria could be present in donor milk unless hygiene rules were followed.

When an infant was fed with donor milk, $68.8 \%$ of the recipient mothers were aware of the possible risks. Of the recipients, $56.3 \%$ stated that they would feed their infant only with the milk obtained from a milk bank instead of Internet groups, and only $56.3 \%$ were aware of the existence of milk banks anywhere around the world.

\section{Related to Risk Management}

It was determined that $75 \%$ of the recipient mothers and $85.4 \%$ of the donor mothers did not enter into any written agreement. Only one of two donor mothers stated that they were aware of the risks of donating milk.

Table 2. Participants' Thoughts on Milk Sharing

\begin{tabular}{|c|c|c|c|c|}
\hline Thoughts & $\begin{array}{l}\text { Recipient } \\
(\mathrm{n}=16) \\
\mathrm{n}(\%)\end{array}$ & $\begin{array}{c}\text { Donor } \\
(\mathrm{n}=48) \\
\mathrm{n}(\%)\end{array}$ & $\begin{array}{c}\text { Those not } \\
\text { involved in } \\
\text { milk sharing } \\
(\mathrm{n}=371) \\
\mathrm{n}(\%)\end{array}$ & $\begin{array}{c}\text { Total } \\
(\mathrm{n}=435) \\
\mathrm{n}(\%)\end{array}$ \\
\hline I'd like to donate milk. & $15(93.8)$ & $48(100)$ & $262(70.6)$ & $325(74.7)$ \\
\hline If necessary, I can feed my infant with donor milk. & $16(100)$ & $38(79.2)$ & $178(48)$ & $232(53.3)$ \\
\hline $\begin{array}{l}\text { I prefer to feed my infant only with the milk obtained from } \\
\text { the milk bank instead of internet groups. }\end{array}$ & $9(56.3)$ & $26(54.2)$ & $200(53.9)$ & $235(54.0)$ \\
\hline I only feed my infant with the milk of the persons I know. & $4(25.0)$ & $10(20.8)$ & $166(44.7)$ & $180(41.4)$ \\
\hline I am aware of milk sharing groups on the internet. & $15(93.8)$ & $35(72.9)$ & $159(42.9)$ & $209(48.0)$ \\
\hline I'm aware of the existence of milk banks. & $9(56.3)$ & $25(52.1)$ & $153(41.2)$ & $187(43.0)$ \\
\hline I am aware of the risks of feeding my infant with donor milk. & $11(68.8)$ & $30(62.5)$ & $186(50.1)$ & $227(52.2)$ \\
\hline I'm aware of the risks of milk donation. & $10(62.5)$ & $24(50.0)$ & $168(45.3)$ & $202(46.4)$ \\
\hline $\begin{array}{l}\text { I would not feed my infant with donor milk because of the reasons } \\
\text { related to milk kinship in Islam. }\end{array}$ & - & $2(4.2)$ & $83(22.4)$ & $85(19.5)$ \\
\hline I would feed my infant with formula instead of someone else's milk. & - & $3(6.3)$ & $56(15.1)$ & $59(13.6)$ \\
\hline $\begin{array}{l}\text { I know that if hygiene rules are not observed, there may be bacteria } \\
\text { that cause diseases in the milk. }\end{array}$ & $14(87.5)$ & $42(87.5)$ & $340(91.6)$ & $396(91.0)$ \\
\hline $\begin{array}{l}\text { If there were a milk bank in Turkey, I would feed my infant with } \\
\text { the milk provided from there in case of need. }\end{array}$ & $11(68.8)$ & $37(77.1)$ & $186(50.1)$ & $234(53.8)$ \\
\hline I believe it is necessary to establish a milk bank in Turkey. & $14(87.5)$ & $45(93.8)$ & $277(74.7)$ & $336(77.3)$ \\
\hline $\begin{array}{l}\text { I think it is inconvenient to establish a milk bank in a Muslim country } \\
\text { in terms of religion. }\end{array}$ & 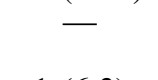 & $5(10.4)$ & $70(18.9)$ & $75(17.2)$ \\
\hline $\begin{array}{l}\text { The only reason I would feed my infant with donor milk because } \\
\text { it is free compared to formula. }\end{array}$ & $1(6.3)$ & $5(10.4)$ & $16(4.3)$ & $22(5.1)$ \\
\hline I'm afraid to feed my infant with someone else's milk. & - & $6(12.5)$ & $137(36.9)$ & $143(32.9)$ \\
\hline
\end{tabular}


Of the recipients, $81.3 \%$ asked their donor mothers about cigarette and alcohol use, $75 \%$ queried the drugs used continuously, and $62.5 \%$ inquired about compliance with hygiene rules while expressing milk.

Of the donors, $87.5 \%$ were never asked about their ethnic origin and culture, $75 \%$ were never asked about their political beliefs, $68.8 \%$ were never asked about their religious beliefs, and $18.8 \%$ were never asked about their detailed health status. With regard to milk kinship in Islam, $75 \%$ of the recipient mothers stated that when choosing donor milk, they never/rarely paid attention to whether or not the infants of the donor mothers belonged to the same gender.

The donor mothers most frequently asked about the recipient's reasons for seeking breast milk $(43.8 \%)$. Of them, $31.3 \%$ inquired about the infant's gender, and $18.8 \%$ wanted to know whether the age of the infants was similar in terms of months (Table 3).

When the participants' concerns about the risks of informal milk sharing were examined, $50 \%$ of the participants in the donor group were worried about sales for profit by the recipient, $47.9 \%$ were anxious about out of purpose use, and $45.8 \%$ were concerned about their responsibility with regard to the recipient infant being negatively affected or contracting a disease.

Fifty percent of the participants in the recipient group were apprehensive about disease transmission, $68.8 \%$ were troubled by the potential drug, cigarette, and alcohol use, and
$37.7 \%$ were nervous about the possible exposure to environmental toxins. Of the recipients, $37.5 \%$ were bothered by the risk of side effects or disease transmission, and $62.5 \%$ were worried about the risks pertaining to hygiene, storage, and transfer conditions (Table 4).

\section{Discussion About Islam and Milk Sharing Practices}

The present investigation determined that three main methods were used to demonstrate the conformity of the milk sharing practice with religion. The first one was for the donor and recipient to ascertain the gender of their infants since same gender babies were unlikely to get married in the future. Therefore, milk sharing among mothers of infants who belonged to the same gender was deemed more suitable in terms of religion.

With regard to the issue of milk kinship in Islam, 75\% of the recipient mothers stated that they did not pay attention to whether or not the infants of the donor and recipient belonged to the same gender when choosing donor milk. However, the level of concern about milk kinship was higher in recipient mothers than in donor mothers. Although the recipients evinced a high level of concern, the fact that $3 / 4$ of this group claimed the lack of attention to this issue suggests that it is not easy to find donor milk, and that when it is found, recipient mothers prefer not to consider gender. In other words, conformity with religion is sought by asking about the gender of

Table 3. Questions About Breast Milk Donation

\begin{tabular}{|c|c|c|c|c|c|}
\hline & Always & Generally & Sometimes & Rarely & Never \\
\hline \multicolumn{6}{|l|}{ Asked questions to donors } \\
\hline Political beliefs and values & & $1(6.3)$ & & $3(18.8)$ & $12(75.0)$ \\
\hline Religious beliefs and values & $2(12.5)$ & $1(6.3)$ & & $2(12.5)$ & $11(68.8)$ \\
\hline Ethnicity and culture & & & & $2(12.5)$ & $14(87.5)$ \\
\hline The willingness to forgive & $10(62.5)$ & $1(6.3)$ & $1(6.3)$ & $1(6.3)$ & $3(18.8)$ \\
\hline Personal advice and references & $2(12.5)$ & $2(12.5)$ & $2(12.5)$ & $3(18.8)$ & $7(43.8)$ \\
\hline Money & & & $1(6.3)$ & & $15(93.8)$ \\
\hline The sex of the baby & $5(31.3)$ & $3(18.8)$ & $4(25.0)$ & $2(12.5)$ & $2(12.5)$ \\
\hline Whether his own baby was milking or not & $2(12.5)$ & $1(6.3)$ & $2(12.5)$ & $1(6.3)$ & $10(62.5)$ \\
\hline Nutrition & $5(31.3)$ & $5(31.3)$ & $1(6.3)$ & $1(6.3)$ & $4(25.0)$ \\
\hline Smoking & $13(81.3)$ & $1(6.3)$ & & & $2(12.5)$ \\
\hline Use of alcohol & $13(81.3)$ & $1(6.3)$ & & & $2(12.5)$ \\
\hline Illegal drug use & $12(75.0)$ & $1(6.3)$ & $1(6.3)$ & & $2(12.5)$ \\
\hline Use of caffeine (tea, coffee, cola) & $5(31.3)$ & $2(12.5)$ & $4(25.0)$ & $1(6.3)$ & $4(25.0)$ \\
\hline Milk enhancing plant, tea use & $3(18.8)$ & $4(25.0)$ & $2(12.5)$ & $2(12.5)$ & $5(31.3)$ \\
\hline Milk enhancing drug & $8(50.0)$ & $1(6.3)$ & $3(18.8)$ & $1(6.3)$ & $3(18.8)$ \\
\hline Exercise status & $1(6.3)$ & $1(6.3)$ & & $6(37.5)$ & $8(50.0)$ \\
\hline Hygiene rules when milking & $10(62.5)$ & $2(12.5)$ & & $1(6.3)$ & $3(18.8)$ \\
\hline Blood test result & $3(18.8)$ & $6(37.5)$ & & $2(12.5)$ & $5(31.3)$ \\
\hline Medical condition of pregnancy & $2(12.5)$ & $3(18.8)$ & $2(12.5)$ & $3(18.8)$ & $6(37.5)$ \\
\hline Detailed health status & $9(56.3)$ & $2(12.5)$ & $1(6.3)$ & $1(6.3)$ & $3(18.8)$ \\
\hline Continuous medications & $12(75.0)$ & $1(6.3)$ & & & $3(18.8)$ \\
\hline Health status of a breastfed child & $9(56.3)$ & & $3(18.8)$ & $1(6.3)$ & $3(18.8)$ \\
\hline Mind-mental health & $4(25.0)$ & $3(18.8)$ & $2(12.5)$ & $2(12.5)$ & $5(31.3)$ \\
\hline Health screening status & $4(25.0)$ & $5(31.3)$ & $2(12.5)$ & $2(12.5)$ & $3(18.8)$ \\
\hline \multicolumn{6}{|l|}{ Asked questions to recipient } \\
\hline Who recommends & $2(12.5)$ & $3(18.8)$ & $4(25.0)$ & $1(6.3)$ & $6(37.5)$ \\
\hline The reason for the search for breast milk & $7(43.8)$ & $3(18.8)$ & $2(12.5)$ & $1(6.3)$ & $3(18.8)$ \\
\hline Religious beliefs and values & $1(6.3)$ & $3(18.8)$ & $2(12.5)$ & $4(25.0)$ & $6(37.5)$ \\
\hline Political beliefs and values & & $1(6.3)$ & $1(6.3)$ & $3(18.8)$ & $11(68.8)$ \\
\hline Ethnicity and cultural characteristics & & $1(6.3)$ & $1(6.3)$ & $3(18.8)$ & $11(68.8)$ \\
\hline The sex of the baby & $5(31.3)$ & $6(37.5)$ & $1(6.3)$ & $2(12.5)$ & $2(12.5)$ \\
\hline Whether the age of babies is in similar months & $3(18.8)$ & $9(56.3)$ & $1(6.3)$ & $1(6.3)$ & $2(12.5)$ \\
\hline
\end{tabular}


Table 4. Concerns of Participants About the Risks of Milk Sharing

\begin{tabular}{lcccr}
\hline & Very & Some & Little & No \\
\hline Thoughts of participants in the donator group & & & & \\
The sales by the recipient for profit & $24(50.0)$ & $8(16.7)$ & $1(2.1)$ & $15(31.3)$ \\
Nonobjective use & $23(47.9)$ & $9(18.8)$ & $4(8.3)$ & $12(25.0)$ \\
Unauthorized disclosure of personal information by the recipient & $13(27.1)$ & $10(20.8)$ & $8(16.7)$ & $17(35.4)$ \\
Concerns over responsibility should the baby you donated & $22(45.8)$ & $15(31.3)$ & $4(8.3)$ & $7(14.6)$ \\
$\quad$ your milk to be affected negatively or develop disease & $7(14.6)$ & $6(12.5)$ & $6(12.5)$ & $29(60.4)$ \\
Negative rumor, gossip & $7(14.6)$ & $5(10.4)$ & $6(12.5)$ & $30(62.5)$ \\
Milk brotherhood & & & & \\
The thoughts of participants in the recipient group & $8(50.0)$ & $3(18.8)$ & $3(18.8)$ & $2(12.5)$ \\
Disease transition & $4(25.0)$ & $4(25.0)$ & $1(6.3)$ & $7(43.8)$ \\
Not the same age of children & $11(68.8)$ & & $2(12.5)$ & $3(18.8)$ \\
Drug use & $11(68.8)$ & $1(6.3)$ & & $4(25.0)$ \\
Smoking & $11(68.8)$ & $1(6.3)$ & $4(25.0)$ \\
Use of alcohol & $6(37.5)$ & $2(12.5)$ & $2(12.5)$ & $6(37.5)$ \\
Exposure to environmental toxins & $5(31.3)$ & $4(25.0)$ & $1(6.3)$ & $6(37.5)$ \\
In the form of a donor's nutrient, substances that may & & & & \\
$\quad$ be allergic to your baby & $4(25.0)$ & $3(18.8)$ & $1(6.3)$ & $8(50.0)$ \\
Disclosure of personal information by donor & $6(37.5)$ & $6(37.5)$ & $1(6.3)$ & $3(18.8)$ \\
Side effects or baby's illness & $1(6.3)$ & $1(6.3)$ & $4(25.0)$ & $10(62.5)$ \\
Negative rumor, gossip & $5(31.3)$ & $1(6.3)$ & $4(25.0)$ & $6(37.5)$ \\
Milk brotherhood & $10(62.5)$ & $3(18.8)$ & $2(12.5)$ & $1(6.3)$ \\
Eligibility of hygiene, storage, and transfer conditions & & &
\end{tabular}

the infant of the donor mother, but in cases when the milk of a mother with an infant of the same gender cannot be found, this criterion may be ignored.

The second method is to limit the number of donors or recipients. According to the Islamic doctrine, receiving milk from more than three donors or giving milk to more than three recipients increases the probability of marriage. This study ascertained that the recipients received milk from an average of $3.62 \pm 3.76$ people in accordance with the Islamic doctrine. In a study conducted by Reyes-Foster et al. ${ }^{5}$ in the United States, a non-Muslim country, a much wider range of number of donors was reported. The difference in the results obtained by the present investigation and the findings of the study by Reyes-Foster et al. ${ }^{5}$ may be explained by the fact that mothers in Turkey tended to conform to religious rules in milk sharing.

The third method is the mutual knowledge of the identities of the donor and the recipient. This method is also significant for the reduction of the risk of contamination. The study by Reyes-Foster et al. ${ }^{5}$ draws attention to widespread milk sharing among people who do not know each other. It states that well-known websites are selected as sources for breast milk to reduce risk. In Palmquist and Doehler's ${ }^{4}$ investigation, $\sim 61.1 \%$ of the recipient mothers reported that they shared milk through the Internet. In comparison with the results obtained by Reyes-Foster et al. ${ }^{5}$ and Palmquist and Doehler, $60.4 \%$ of the donors in the present study stated that they made their donations through sharing sites on the Internet.

In a study conducted with 1,042 women in Turkey, Karadag et al. ${ }^{3}$ reported that if needed, $12.6 \%$ of the participants would feed their infants with donor milk without querying the donor's identity. The present investigation found this rate to be $79.2 \%$ in donors and $48 \%$ in those who were not involved in milk sharing. Although the two studies are similar in terms of the mean age, perhaps the women in the present study were more advanced in their level of education, and hence, the difference is caused by the variance in the educational quali- fications of the mothers. Furthermore, $10.6 \%$ of the mothers participated in prenatal breastfeeding classes, and $26.2 \%$ of the mothers participated in postnatal breastfeeding support groups. Of the participants, $13.6 \%$ stated that they received postnatal breastfeeding counseling. Hence, they may be adjudged to be more knowledgeable about breastfeeding.

Donor and recipient mothers never questioned religious beliefs, ethnic origins, or political beliefs while giving or receiving milk. It can thus be observed that Turkish mothers involved in milk sharing in this study provided and used breast milk without any significant consideration for religious belief, political affiliation, or ethnic origin. This result demonstrates that the sample group shared milk regardless of religion, ethnicity, culture, or political leanings.

Recipient mothers mostly seek donor milk because of a notion of the mother's milk insufficiency rather than the infant's condition. In the study conducted by Palmquist and Doehler, ${ }^{4} 42.2 \%$ of the recipients reported that they fed donor milk due to milk insufficiency. Similarly, in this study, milk was sought mostly due to milk insufficiency $(87.5 \%)$.

A large proportion of the mothers not involved in milk sharing reported that they were worried about disease transmission, while $19.5 \%$ of them claimed that they would not feed their infant with donor milk because of reasons related to milk kinship in Islam. This rate is similar to the outcomes obtained by Karadag et al. ${ }^{3}$

\section{Discussion About Risk Management}

The literature mentions bacterial contamination, substances that can be mixed with milk, and conditions such as drug use, as the most important risks of informal milk sharing. ${ }^{4,6-8}$ The low rate of undertaking written agreements observed in the current study proves that milk sharing is accomplished by informal means and through the acceptance of risks. 
The recipients questioned the donor's health screening status, detailed health condition, medical circumstances of pregnancy, cigarette and alcohol use, drugs continuously used, and compliance with hygiene rules during milk expression. A study on milk sharing risk perceptions conducted with 867 women in the United States reported that $9.3 \%$ of recipient mothers did not insist on prospective donor screening. ${ }^{4}$ The ABMs milk sharing protocol emphasizes that the medical history of a donor should be questioned in detail and, if possible, her prenatal screening tests and social behaviors should be evaluated. ${ }^{9}$ This study found that the milk sharing risk reduction strategy of donor screening is not at an ideal level, but is not completely inadequate.

None of the recipient and donor mothers in this study reported that they exchanged milk for money. Reyes-Foster et al. ${ }^{5}$ also stated that money exchange was rarely encountered in their study. Keim et al. ${ }^{10}$ found out that breast milk sold for money on the Internet was diluted with cow's milk to generate more income. In another study conducted in 2013, the same researcher reported that a high level of bacterial contamination was found in milk purchased online. ${ }^{6} \mathrm{Al}-$ though milk sharing was accomplished mostly on the Internet in the present study, milk was not sold, and the current investigation's finding of opposition to the sale of breast milk for money is similar to the results obtained by other studies. ${ }^{3,5}$

The respondents of the present investigation reported that face-to-face delivery by donors to recipients was the most frequently used milk delivery method (83.3\%) and this outcome is similar to the results observed by Reyes-Foster et al. ${ }^{5} 95.8 \%$ of the donors in the present study reported that they used coolpacks or cooling containers when delivering the milk to be donated. These issues are highlighted in the ABMs protocol on milk storage to prevent contamination, which states that the structure of milk may alter if appropriate conditions are not met. ${ }^{9}$

In addition, this study determined that high rates of herbal supplements were taken by donors to increase milk production. However, it is noteworthy that this condition was not perceived as a risk factor by recipients, who ignored the possibility that herbal supplements taken in an uncontrolled manner and without the knowledge of agonist-antagonist interactions may cause medical problems in susceptible infants.

All the recipient mothers who participated in the study were forced to choose informal breast milk sharing despite their desires to the contrary. In other words, half of the recipient mothers were involuntarily engaged in informal breast milk sharing because there is no milk bank alternative in Turkey.

\section{Conclusions}

This study found out that donors often donate and share their breast milk to help someone and to put their excess milk to good use. On the contrary, recipients are often engaged in milk sharing primarily because of perceived milk insufficiency. One of every four or five mothers in this study evinced some concern as to the Muslim beliefs about milk sharing. The religious rules on milk sharing are reflected in three ways in those engaged in informal milk sharing transactions: asking about the gender of the donor's or recipient's infant, limiting the number of sharing parties to 3 , and establishing a mutual awareness of each other's identity.

Most of the breast milk sharing was done via the internet. For the most part, there was no written milk sharing agree- ment between the donor and the recipient, the donor's health screening was not fully demanded. The results obtained by this study also noted that milk sharing among this selected group of mothers was relatively free from religious concerns and commercial purposes. However, ideal measures were not taken to prevent disease transmission. Finally, the study ascertained that there is a population of mothers in Turkey who agree that a milk bank is needed and are positive about the potential establishment of such an institution in their country.

\section{Acknowledgments}

We thank Charlotte Codron, Aunchalee E. L. Palmquist, and Kirsten Doehler for their contribution to the preparation of the questionnaires.

\section{Disclosure Statement}

No competing financial interests exist.

\section{References}

1. WHO. Global strategy for infant and young child feeding. Available at http://whqlibdoc.who.int/publications/2003/ 9241562218.pdf?ua=1 (accessed March 27, 2014).

2. Khalil A, Buffin R, Sanlaville D, et al. Milk kinship is not an obstacle to using donor human milk to feed preterm infants in Muslim countries. Acta Paediatr 2016;105:462-467.

3. Karadag A, Ozdemir R, Ak M, et al. Human milk banking and milk kinship: Perspectives of mothers in a Muslim country. J Trop Pediatr 2015;61:188-196.

4. Palmquist A, Doehler K. Human milk sharing practices in the U.S. Matern Child Nutr 2016;12:278-290.

5. Reyes-Foster B, Carter S, Hinojosa M. Milk sharing in practice: A descriptive analysis of peer breastmilk sharing. Breastfeed Med 2015;10:263-269.

6. Keim SA, Hogan JS, McNamara K, et al. Microbial contamination of human milk purchased via the internet. $P e$ diatrics 2013;132:e1227-e1235.

7. Timmins F, O'Shea J. The Roper-Logan-Tierney (1996) model of nursing as a tool for professional development in education. Nurse Educ Pract 2004;4:159-167.

8. Geraghty S, McNamara K, Dillon C, et al. Buying human milk via the Internet: Just a click away. Breastfeed Med 2013;8:474-478.

9. Sriraman NK, Evans AE, Lawrence R, et al.; Academy of breastfeeding medicine's board of directors. Academy of breastfeeding medicine's 2017 position statement on informal breast milk sharing for the term healthy infant. Breastfeed Med 2018;13:2-4.

10. Keim S, Manjusha K, McNamara Kea. Cow's milk contamination of human milk purchased via the Internet. Pediatrics 2015;135:e1157-e1162.

Address correspondence to: Güliz Onat, PhD Department of Midwifery College of Health Science KTO Karatay University Konya 42020 Turkey

E-mail: gulizonat@hotmail.com 